\title{
METHODOLOGICAL VALIDATION FOR THE DETERMINATION OF TOXIC ARSENIC SPECIES IN HUMAN URINE USING HPLC WITH ICP-MS
}

\author{
LUIS MUÑOZ ${ }^{*}$, MACARENA MENESES ${ }^{l}$, PAOLA PISMANTE ${ }^{l}$, OSCAR ANDONIE ${ }^{l}$, \\ FABRIZIO QUEIROLO' ${ }^{2}$ SUSANA STEGEN ${ }^{2}$
}

\author{
${ }^{I}$ Nuclear Aplication Department, Comisión Chilena de Energía Nuclear, Amunátegui 95, Santiago, Chile. \\ ${ }^{2}$ Chemistry Department, Universidad Católica del Norte, Av. Angamos 0610, Antofagasta CL 1240000, Chile.
}

\begin{abstract}
There is a significant amount of arsenic species in the environment and in biological systems; however, the toxicity and possibly the carcinogenicity of ingested arsenic depend on the species and the oxidation state. Therefore, analytical methodologies and techniques that are fast and robust, that involve highly efficient separation and are powerful tools of detection are necessary for the correct quantification of individual arsenic species. The field of speciation analysis of arsenic in this area has grown rapidly in recent years, especially with the application of liquid chromatography and mass spectrometry with inductively coupled plasma. This study aimed to develop and apply this technique to human urine samples in order to reduce the treatment needed for speciation, maintain maximum recovery and avoid interconversion and / or degradation between species. In order to optimize the separation of species, several experiments were performed by preparing the mobile phase at different $\mathrm{pH}$ values. The optimal $\mathrm{pH}$ value and the linearity of the method were determined and the methodology was validated using a Certified Reference Material. Student's t-test and Fisher F-test for determination of accuracy and precision were applied. A simple, rapid and reliable method for the separation and quantification of several species of arsenic, As III (Arsenite), As V (Arsenate), MMA (Monomethyl Arsonic Acid), DMA (Dimethyl Arsinic Acid), $\mathrm{AB}$ (Arsenobetaine) was developed in human urine samples with minimal prior sample preparation. The time required for sample processing and isocratic

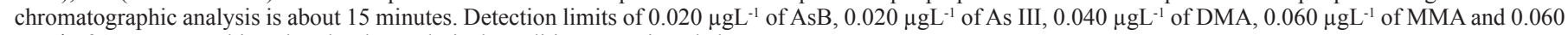
$\mu \mathrm{gL}^{-1}$ of As V were achieved under the analytical conditions mentioned above.
\end{abstract}

Keywords: methodological validation, arsenic species, human urine, HPLC, ICP-MS

\section{INTRODUCTION}

According to estimates from the studies office of the Copper Chilean Commission -COCHILCO- mining investments in Chile are the highest in Latin America, at US\$ 16 billions, surpassing Brazil, Peru and Argentina ${ }^{1}$. However, byproducts, such as arsenic associated with mining and volcanism constitutes an enormous environmental and occupational problem in the country. The mortality statistics for lung cancer, bladder cancer and female reproductive tract cancer, in mining towns in the northern Chile, significantly exceed the national average ${ }^{2}$.

The cancer records in Antofagasta, show 1,110 annual cases of cancer with 500 to 600 cancer deaths per year. The most important are: skin, lung, breast and bladder ${ }^{3}$. People who were exposed to high intakes of arsenic in drinking water (about 260,000 habitants), remain at high risk of developing bladder cancer. In 2009, there were 6 cases of cancer recorded country-wide per 100,000 men, while in the city of Antofagasta, there were 16 cases per 100,000 men.

The same is true for women: 2.5 cases of bladder cancer per 100,000 women in Chile, and 13.5 cases per 100,000 women in Antofagasta ${ }^{4}$.

The Regional Council as well as the Regional Director of the National Environment Commission, has asked universities and other institutions, to carry out studies dealing with this problem. Approximately $97 \%$ of the population in Antofagasta Region were exposed for 20 years $(1950-1978)$ to high levels of arsenic in drinking water $\left(90-860 \mu \mathrm{gL}^{-1}\right)$. Between 1979 and 2003 , the level dropped to arsenic ${ }^{5} 50 \mu \mathrm{gL}^{-1}$, and from 2003, drinking water has had a concentration of As $10 \mu \mathrm{gL}^{-1}$. This problem is even more serious in the water that supplies Chilean highland villages ${ }^{6}$, where arsenic levels of up to $2 \mathrm{mgL}^{-1}$ have been found. Due to all the above, Chilean health authorities need to have a methodology to quickly, precisely and accurately determine the arsenic species.

Current health regulations use the levels of total arsenic in urine but arsenic toxicity is strongly dependent on the species present in a sample. Chemical arsenic species are an important indicator for revealing the degree of exposure to "non-dietary" arsenic, that is, inorganic arsenic with methylated metabolite. The inorganic arsenic species arsenite and arsenate have been related to an increased risk of cancer as well as to cardiovascular diseases, whereas methylated forms of arsenic such as methylarsonic acid (MMA) and dimethylarsinic acid (DMA) are significantly less toxic. Other species such as arsenobetaine and arsenocholine are essentially non-toxic ${ }^{7}$. The major route for the excretion of As is via urine and for human biomonitoring urine is mostly recommended for the speciation of As. The concentration of urinary species mainly reflects recent exposure (a few hours to 2 days). In healthy and occupationally non-exposed subjects the concentration of urinary As species varies, mainly depending on the arsenic concentration in drinking water and the amount of seafood in the diet. Seafood often contains high concentrations of organoarsenicals of negligible toxicity. Typically this is arsenobetaine, which is rapidly excreted in urine as unchanged molecule. Unlike arsenobetaine inorganic arsenic is toxic and carcinogenic. The inorganic form arsenite and arsenate are absorbed orally and by inhalation. In the body inorganic arsenic undergoes enzymatic methylation to MMA and DMA, which is mainly excreted in urine together with As III and As V.

The residence time of the inorganic arsenic in the body is about 4 to 5 days, and only after a long period of ingesting As in water do the first effects appear, usually on the skin. These effects are estimated to appear after a long exposure of 5-15 years for doses of inorganic As of $0.01 \mathrm{mg} \mathrm{kg}^{-1}$ per day and $0.5-3$ years for doses superior to $0.04 \mathrm{mg} \mathrm{kg}^{-1}$ per day. The effects in the population vary, but between $5 \%$ and $10 \%$ of people are thought to be affected after 10 - 15 years of exposure ${ }^{8}$.

The following validation parameters were determined: Accuracy, Precision, Linearity, Limits of Detection and Uncertainty.

The development, validation and application of this methodology will help public health monitoring in Chile, by allowing the determination of arsenic species in urine to be used as a biological indicator of occupational and environmental exposure.

\section{EXPERIMENTAL}

\section{Instrumentation}

For the determination of As, an Agilent ICP-MS, model 7500, equipped with a Babington nebulizer system, Fasel torch, Scott double pass spray chamber cooled by a Peltier thermoelectric module and quadrupole analyzer was used as an online chromatographic detector. The chromatographic system consisted of a Waters 600E HPLC isocratic pump and a PRP-X100 anion exchange column (Hamilton, Reno, NV, USA). The effluent from the column was introduced directly into the nebulizer through a Teflon capillary tube. All the tubing and outlets in contact with the mobile phase were made of inert polyether ether ketone (PEEK) materials. Data were collected using the time resolved analysis mode of Agilent software.

A single ion of $\mathrm{m} / \mathrm{z} 75$ was used for data collection. The signal at $\mathrm{m} / \mathrm{z} 77$ and 82 were monitored concurrently in order to evaluate possible polyatomic 
interferences of $\mathrm{ArCl}^{+}$.

Table 1 shows the operating conditions of the ICP-MS and chromatographic parameters.

Table 1. Instrumental parameters for the determination of arsenic species.

\section{ICP-MS}

RF Power:

Argon Flow:

$1200 \mathrm{~W}$

Isotope measured: Integration Time:

Peak points:

Plasma Gas: $16 \mathrm{~L} / \mathrm{min}$

Nebulizer: $1.06 \mathrm{~L} / \mathrm{min}$

As-75, $\mathrm{ArCl}^{+}$, Se-82

$0.1 \mathrm{~s}$ (spectrum) per point

10

IC

Column:

PRP-X100 anion exchange

Dimensions: $250 \mathrm{~mm}$ x $4.1 \mathrm{~mm}$

Particle size: 10 um

Pre-column:

PRP-X100 anion exchange

Dimension: $4.6 \mathrm{~mm}$

$10 \mathrm{mM} \mathrm{HPO}_{4}^{-2}, \mathrm{H}_{2} \mathrm{PO}_{4}^{-1}$

Mobile Phase:

Injection Volume:

Flow rate:

$100 \mu \mathrm{L}$

$1 \mathrm{~mL} / \mathrm{min}$

Mode:

Isocratic

\section{$\underline{\text { Reagents and standards }}$}

For the preparation of samples and standards, high purity deionized water was used. Arsenic solutions were prepared using the following compounds: $\mathrm{As}_{2} \mathrm{O}_{3}$ (As III) from J.T. Baker (Deventer, Holland), $\mathrm{Na}_{2} \mathrm{HAsO}_{4}$ (As V) from Merck (Darmstadt, Germany). MMA and DMA were prepared in $4 \% \mathrm{HNO}_{3}$ by dissolving adequate amounts of $\mathrm{CH}_{3} \mathrm{AsO}_{2} \mathrm{Na}_{2}(\mathrm{MMA})$ and $\left(\mathrm{CH}_{3}\right)_{2} \mathrm{AsO}_{2} \mathrm{Na}_{3} 3 \mathrm{H}_{2} \mathrm{O}$ (DMA), both $98 \%$ purity from Merck (Darmstadt, Germany). Arsenobetaine from Sigma Aldrich (Seelze, Germany).

All solutions were stored in high density polyethylene bottles and maintained at a temperature of $4{ }^{\circ} \mathrm{C}$. Working solutions were prepared daily.

The mobile phase used was a buffer solution prepared by dissolving appropriate amounts of salts $\mathrm{HPO}_{4}^{-2} / \mathrm{H}_{2} \mathrm{PO}_{4}^{-1}$ (Merck, Darmstadt) $+3 \%$ ethanol (EtOH), for a $10 \mathrm{mM}$ solution, which was adjusted with $\mathrm{KOH}$ to different $\mathrm{pH}$ values. EtOH increases the signal to background ratio. Scandium, purchased from Merck (Darmstadt, Germany), was used as an internal standard.

\section{Samples}

The first morning urine was considered. $10 \mathrm{ml}$ of the middle stream urine in a sterile container were collected. The samples were kept at $4^{\circ} \mathrm{C}$ in darkness until use. If the sample has to be stored for several days, it should remain frozen at $-4^{\circ} \mathrm{C}$ to $-20^{\circ} \mathrm{C}$ without any additives.

In order to validate the analytical methodology, reference material NIST 2669, Arsenic Species in Frozen Human Urine, was selected. The material was thawed just two hours before being analyzed. Prior to analysis, all the samples were filtered through an Acrodisc $0.45 \mu \mathrm{m}$ syringe filter Sigma-Aldrich (Seelze, Germany), followed by a 1-5 dilution with deionized water ${ }^{9}$. Dilution can prevent the salts in urine samples from affecting the separation of arsenic species, and minimize the possible interference from $\mathrm{ArCl}^{+}$.

\section{RESULTS AND DISCUSSIONS}

\section{Enhancing Sensitivity}

The influence of the introduction of organic modifier (ethanol or methanol) on the arsenic response in ICP-MS for different flow rates was studied. For each flow rate, the ICP-MS parameters were optimized, detection was achieves in "scanning mode".

The results are shown in Fig 1. When adding small amounts of 3\% ethanol as a modifier, there signal increased, but when the ethanol concentration was increased, the signal decreases drastically. The best signal intensities are observed in low-flow rates with an ethanol concentration of 3\%. These observations are consistent with those made by Demesmay et al. ${ }^{10}$ who confirmed that at high concentrations of ethanol the plasma instability no longer allows a reproducible measurement and the carbon built-up on the sampler cone leads to progressive clogging of the interface and subsequently to a decrease of the signal over time. This is also consistent with Shum et $\mathrm{al}^{11}$. who studied the influence of the introduction of methanol with a specific sample introduction device. These results show that for moderately ionizabled elements such as arsenic, the signal intensity greatly depends on the organic composition of the solution and on the introduction flow rates. The decrease of the signal in the presence of high concentrations of organic solvent is related to a decrease in the efficiency of ionization. Allain et $\mathrm{al}^{12}$. have observed a significant increase in the signal of some elements in the presence of carbon (such as glycerol), which is attributed to a shift in the ionization equilibrium. This same phenomenon was observed when small amounts of methane were added into the plasma and was only observed for elements with a relatively high ionization energies ranging from 9 to $11 \mathrm{eV}$ (arsenic ionization energy = $9.8 \mathrm{eV})$.

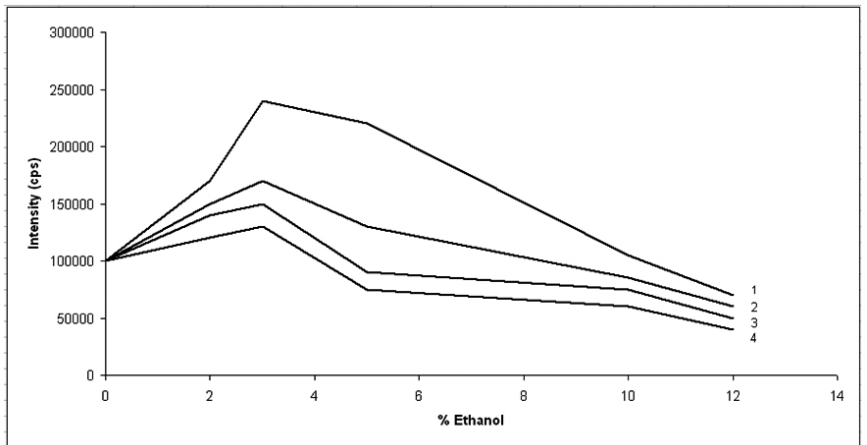

Fig. 1. Influence of the organic solvent concentration on the ICP-MS response at different introduction flow rates; $\mathrm{As}=50 \mu \mathrm{gL}^{-1} ; 1=0.5 \mathrm{ml} \mathrm{min}{ }^{-1} ; 2$ $=1.0 \mathrm{ml} \mathrm{min}^{-1} ; 3=1.5 \mathrm{ml} \mathrm{min}^{-1} ; 4=2.0 \mathrm{ml} \mathrm{min}{ }^{-1}$

\section{Chromatographic Separation}

The physico-chemical properties of the principal species play an important role in the liquid chromatographic separation. Inorganic species and their methylated forms are polar weak acids; arsenobetaine is a weak acid with a permanent positive charge on the arsenic atom. All these properties create difficulties when choosing the chromatographic conditions whatever the separation mode. Table 2 shows that anionic arsenic species have very different acidity constants ${ }^{13}$. This is an advantage in the separation of these solutes by ionexchange. Arsenic III has an elevated $\mathrm{p} K$ a value, so that it remains un-ionized in the $\mathrm{pH}$ range generally allowed $(\mathrm{pH} 2-8)$ for the common chromatographic stationary bonded phases. In this $\mathrm{pH}$ range, the anionic species As V, DMA and MMA are retained in the column and are well separated, whereas the As III un-ionized species elutes in the dead volume. In the anion exchange mode and in the same $\mathrm{pH}$ range of 2-8, As III is eluted with the same retention time as arsenobetaine (either a cationic or a zwitterion, depending on the $\mathrm{pH}$ value). A mobile phase with a high $\mathrm{p} K$ value and a high $\mathrm{pH}$ range would be desirable for increased the ionization and consequently better separation. Several authors ${ }^{7,14,15}$ have been able to separate these five arsenic species using an anion exchange column with a neutral phosphate buffer $\mathrm{HPO}_{4}^{-2}$ and $\mathrm{H}_{2} \mathrm{PO}_{4}^{-1}$ as a mobile phase ( $\mathrm{p} K$ 6.8). When we tried to use this buffer at $\mathrm{pH} 7.5$ as a mobile phase with a PRP X-100 column, As III and arsenobetaine were not separated. As V, MMA and DMA were successfully separated, as shown in Figure 2.

Table 2. $\mathrm{p} K_{\mathrm{a}}$ of Arsenic species

\begin{tabular}{|l|l|}
\hline Compound & $\mathbf{p} \boldsymbol{K}_{\mathbf{a}}$ \\
\hline As (III) & 9.2 \\
\hline Arsenic acid As (V) & $2.3 ; 6.8 ; 11.6$ \\
\hline Monomethylarsonic acid (MMA) & $3.6 ; 8.2$ \\
\hline Dimethylarsinic acid (DMA) & $1.3 ; 6.2$ \\
\hline Arsenobethaine (Asbet) & 2.2 \\
\hline
\end{tabular}

In order to optimize and improve the separation of arsenic species, particularly the separation of As III and arsenobetaine, different elutions were performed by preparing the phosphate mobile phase at different $\mathrm{pH}$ values, which were used with mixtures of $10 \mu \mathrm{gL}^{-1}$ of each of the species. 
The mobile phase was adjusted with $\mathrm{KOH}$ to the following $\mathrm{pH}$ values: 8.4, 8.7, 9.3, and 9.7. According to experimental results, the mobile phase was prepared with $3 \%$ ethanol and the flow rate was adjusted to $1 \mathrm{ml} /$ minute. When elution was performed at $\mathrm{pH} 8.4$ all the retention times decreased and separation is successful for all arsenic species and a quantifiable separation between arsenobetaine and As III is obtained. By increasing the $\mathrm{pH}$ value of the mobile phase, the retention time remained almost unchanged but the resolution between the signals of As III and DMA decreased dramatically as shown in Figure 3. The best separation was achieved when the mobile phase $\mathrm{pH}$ was 8.4. The retention times at $\mathrm{pH} 8.4$ can be seen in table 3 .
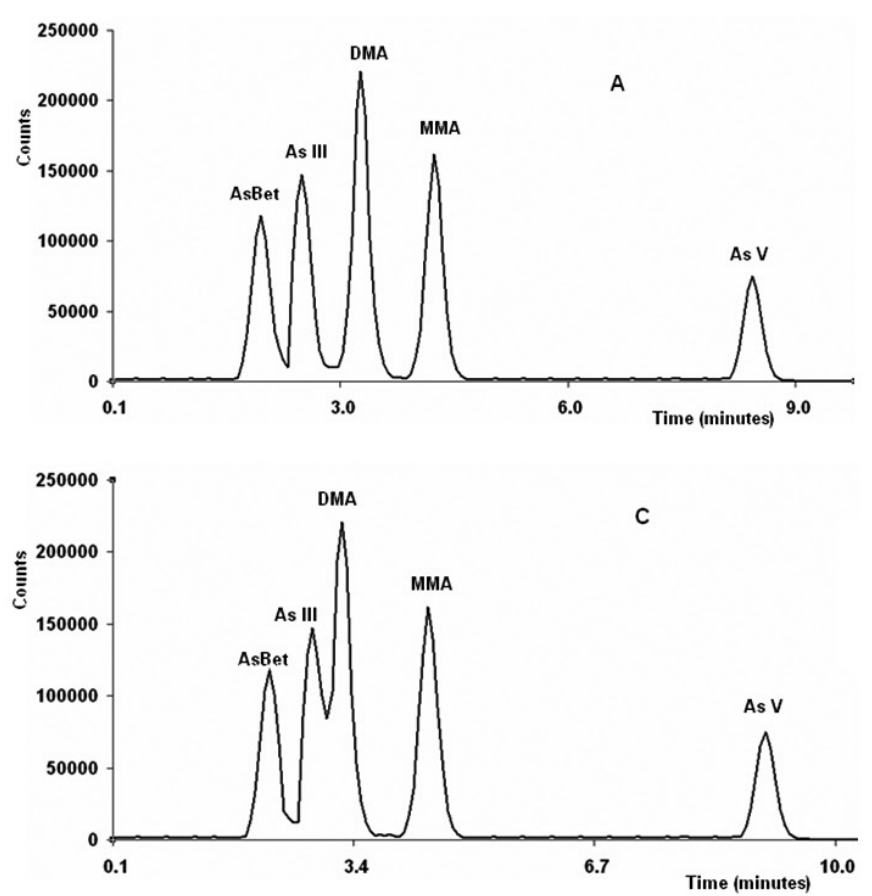

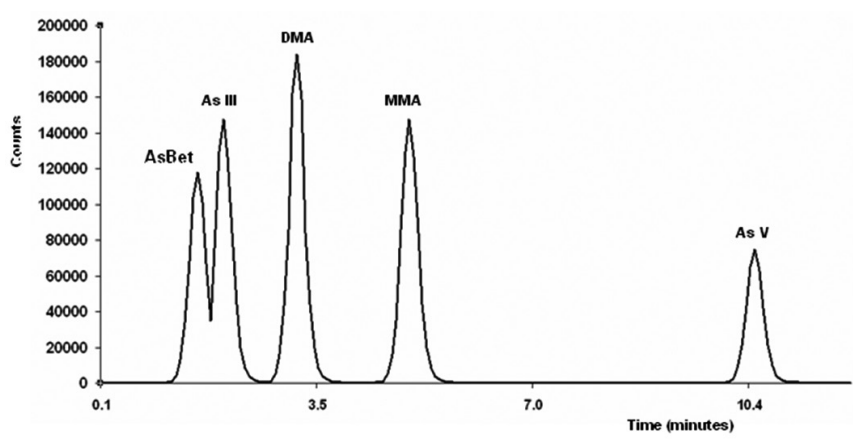

Fig. 2. Chromatogram of the mixture of 5 arsenic species
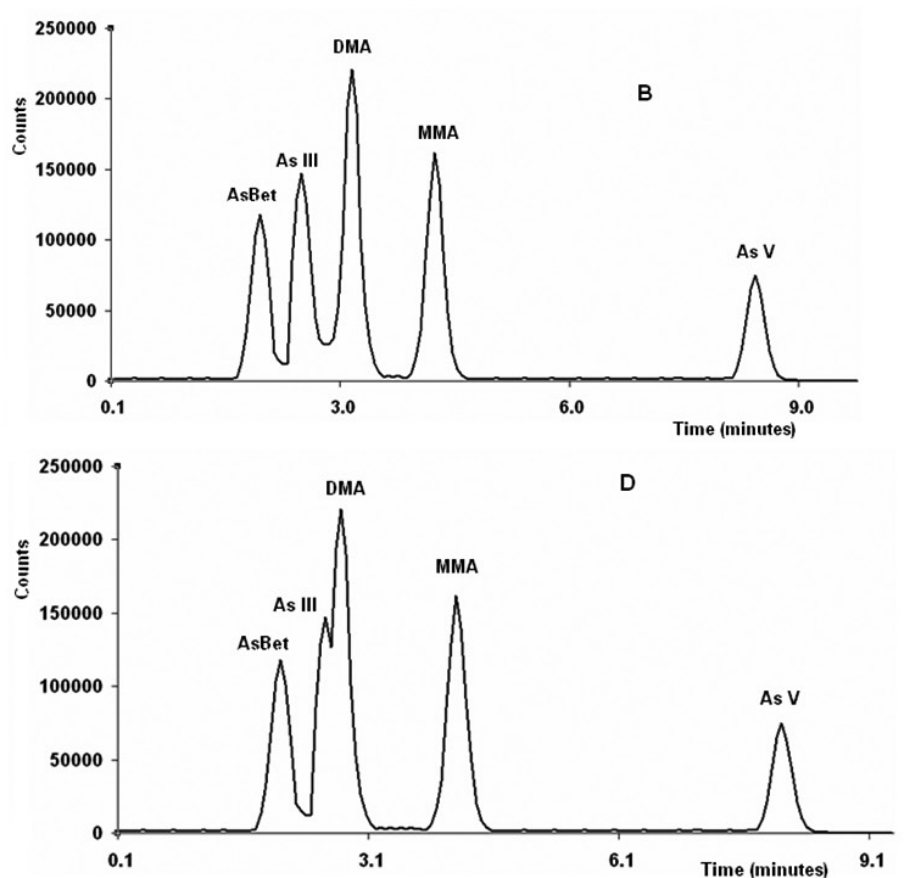

Fig. 3. Elution chromatograms with phosphate mobile phase at different $\mathrm{pH}$ values. $\mathrm{A}=\mathrm{pH} 8.4 ; \mathrm{B}=\mathrm{pH} 8.7 ; \mathrm{C}=\mathrm{pH} 8.9 ; \mathrm{D}=\mathrm{pH} 9.3$

Table 3. Retention time at $\mathrm{pH} 8.4$

\begin{tabular}{|c|c|}
\hline Specie & Retention time (min) \\
\hline Arsenobetaine & 2.32 \\
\hline Arsenic III & 2.72 \\
\hline DMA & 3.20 \\
\hline MMA & 4.16 \\
\hline Arsenic V & 8.32 \\
\hline
\end{tabular}

Before starting the HPLC-ICPMS system, an aqueous arsenic solution of $10 \mu \mathrm{gL}^{-1}$ (as atom) was aspirated in order to optimize the sensitivity of the apparatus.

\section{NaCl Contribution}

Human urine sodium chloride content is about $0.15 \mathrm{~mol} \mathrm{~L}^{-1}$ (or approximately $0.6 \%$ by mass). Assuming normal levels of As in urine of 100 $\mu \mathrm{gL}^{-1}$ or lower, chloride concentrations would be approximately $10^{5}$ times more concentrated than any of the As species present. Due to the high chloride concentration in urine, interference from coeluting $\mathrm{Cl}$ forming $\mathrm{ArCl}^{+}(\mathrm{m} / \mathrm{z}=$ 75) could be a significant problem with the analysis of As in urine. As a result, it is necessary to evaluate the real interference of chlorine. Therefore, the peak intensity generated by a $50,000 \mu \mathrm{gL}^{-1}$ solution of chlorine was measured.

The elution chromatogram in Figure 4 shows that this high concentration of chlorine causes a negligible interference, and may interfere only minimally in the determination of Arsenic $\mathrm{V}$, since the peak chlorine from $\mathrm{ArCl}^{+}$, appears to 8.50 seconds.

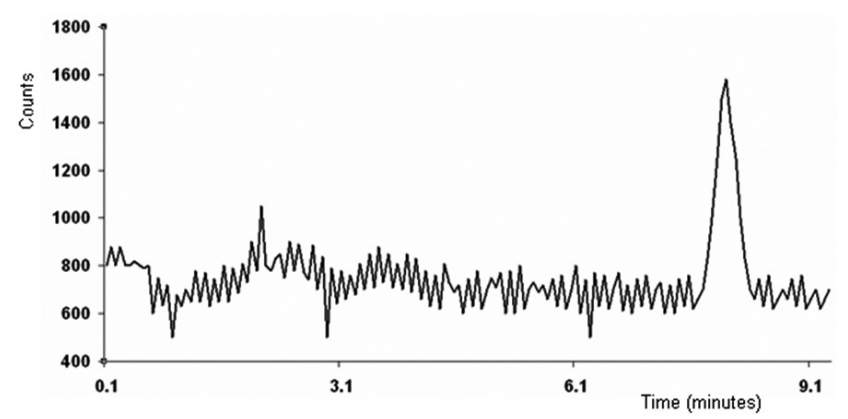

Fig 4. Chromatogram of $50,000 \mu \mathrm{gL}^{-1}$ chlorine.

According to the calibration curve, the area of this signal is equivalent to 
$0.1 \mathrm{ng}$ of Arsenic $\mathrm{V}$ for $100 \mu \mathrm{L}$ sample injection.

Validation

In order to validate this HPLC-ICP-MS method ${ }^{16}$, under these optimized conditions Certified Reference Material NIST 2669, Arsenic Species in Frozen Human Urine was analyzed. The chromatogram from this analysis is shown in Figure 5. Table 4 summarizes the species content for this Certified Reference Material. These results were used to determine the method's accuracy and precision.

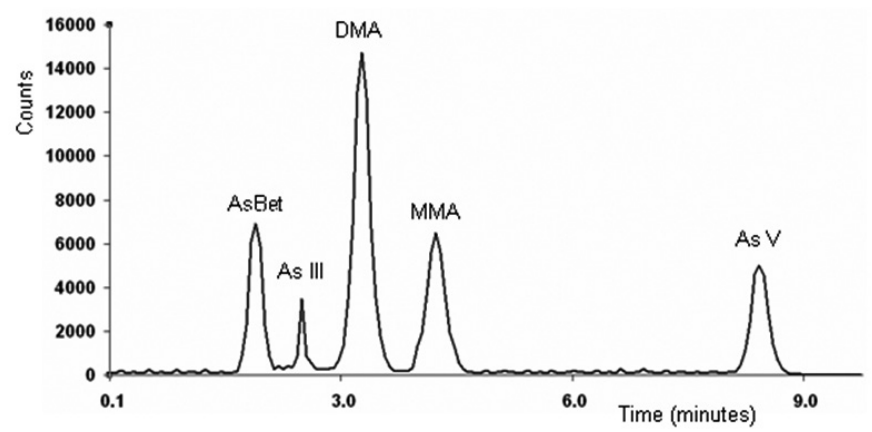

Fig 5. Chromatogram of CRM NIST 2669

Table 4. Comparison between the values reported by CRM NIST 2669 and those obtained by applying the methodology studied.

\begin{tabular}{|c|c|c|c|}
\hline Specie & $\begin{array}{c}\text { Certificate } \\
\text { Value }\left(\boldsymbol{\mu g L} \mathbf{L}^{-1}\right) \\
\pm \mathbf{U}\end{array}$ & $\begin{array}{c}\text { Obtained } \\
\text { Value }\left(\boldsymbol{\mu g L} \mathbf{L}^{-1}\right) \\
\pm \mathbf{U}\end{array}$ & \% Recovery \\
\hline Arsenobetaine & $1.43 \pm 0.08$ & $1.57 \pm 0.14$ & 109 \\
\hline Arsénic III & $5.03 \pm 0.31$ & $4.82 \pm 0.18$ & 95.8 \\
\hline Arsénic V & $6.16 \pm 0.95$ & $7.05 \pm 0.58$ & 114 \\
\hline MMA & $7.18 \pm 0.56$ & $6.68 \pm 0.37$ & 93.0 \\
\hline DMA & $25.3 \pm 0.70$ & $23.3 \pm 1.3$ & 92.1 \\
\hline
\end{tabular}

Accuracy

An analytical method has good accuracy when after analysis with a reference material, it yields results that are no different from the certified values beyond the statistical fluctuations defined by the method ${ }^{17}$.

Student's t-test was applied to the results which determined that most of the measurements show no statistically significant difference between the values obtained and the certified values. A summary of this application is shown in Table 5 .

Table 5. Student's t-test applied to the results of the analysis of the reference material. Weighted $\mathrm{t}$ value for 3 degrees of freedom and $95 \%$ confidence level $=3.18$

\begin{tabular}{|c|c|c|}
\hline Specie & t Value Calculated & $\begin{array}{c}\text { Are there significant } \\
\text { differences? }\end{array}$ \\
\hline Arsenobetaine & 2.00 & NO \\
\hline Arsénic III & 2.33 & NO \\
\hline Arsénic V & 3.07 & NO \\
\hline MMA & 2.70 & NO \\
\hline DMA & 2.67 & NO \\
\hline
\end{tabular}

\section{Precision}

An analytical method has good precision when analyzing a reference material, producing results that are statistically as accurate as those given in the certification document ${ }^{17}$. This determination can be made if the reference material gives the standard deviation of the certified value. Otherwise, accuracy cannot be determined using reference materials. To determine the precision, the homogeneity of variances test known as Fisher's F-test was applied.

Fisher's F-test was applied to the analytical results and determined that in all cases where it was applied the calculated $\mathrm{F}$ value is less than the tabulated value. For this reason, it can be argued that the method is precise. A summary of this application is shown in Table 6.
Table 6. : Statistical F-test applied to the results of the analysis of reference materials. Weighted values for $\mathrm{F}$ (quotient of variances) corresponding to $95 \%$ confidence level for n-1 degrees of freedom.

\begin{tabular}{|c|c|c|}
\hline Species & F Value Calculated & F Value Tabulated \\
\hline Arsenobetaine & 3.06 & 4.05 \\
\hline Arsénic III & 2.97 & 4.05 \\
\hline Arsénic V & 2.68 & 4.05 \\
\hline MMA & 2.29 & 4.05 \\
\hline DMA & 3.44 & 4.05 \\
\hline
\end{tabular}

\section{Linearity}

Linearity is defined as the ability of an analytical method to respond with the same accuracy in the determination of different concentrations of the same analyte ${ }^{17}$.

Using the best separation conditions, the linearity of the relationship between the concentrations of the species was evaluated.

In Figure 6 overlapping chromatograms for 5,10 and $20 \mu \mathrm{gL}^{-1}$ of the mixture of species are observed. Figure 7 shows the calibration curves and the parameter $\mathrm{R}$ value for each of the species. The corresponding correlation coefficients obtained after a linear regression range from 0.9994 to 0.9999 . The results show that the ICP-MS is characterized by its wide dynamic linear range.

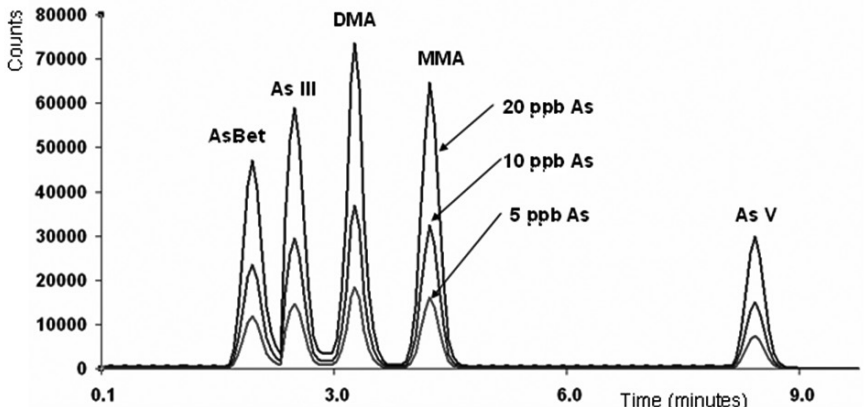

Fig 6. Chromatograms with different arsenic species concentration

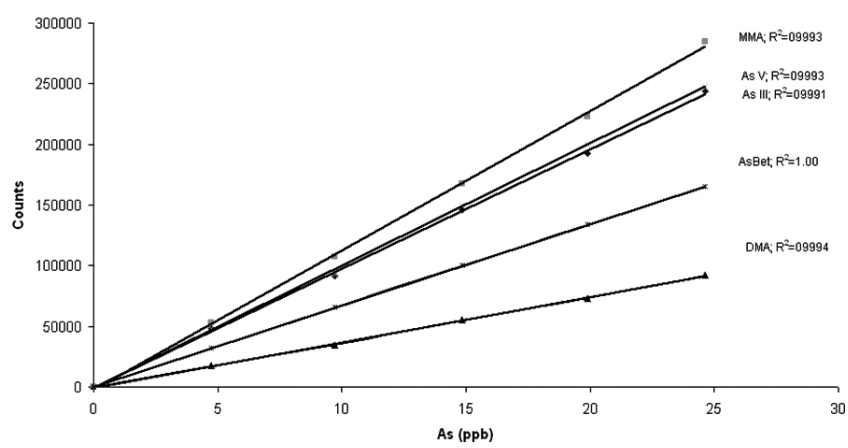

Fig 7. Calibration curves for each of the species.

\section{Limit of Detection}

The detection limit is defined as the smallest concentration or amount of a component of interest that can be measured with a certain confidence level ${ }^{17}$.

According to this definition, the limits of detection (LOD) estimated as three times the standard deviation of six replicate measurement of a standard solution with the lowest concentration of species whose peaks can be distinguished from the baseline noise are given in Table 7. In these experiments, a $0.2 \mu \mathrm{gL}^{-1}$ solution was used to evaluate the detection limits. 
Table 7. Detection limit (LOD) are based on three times the amplitude of the baseline noise and are given for the compounds without their respective counter-ions

\begin{tabular}{|c|c|}
\hline Specie & LOD $\boldsymbol{\mu} \mathbf{g L}^{-1}$ \\
\hline Arsenobetaine & 0.020 \\
\hline Arsenic III & 0.020 \\
\hline DMA & 0.040 \\
\hline MMA & 0.060 \\
\hline Arsenic V & 0.060 \\
\hline
\end{tabular}

\section{Uncertainty}

Uncertainty is defined as a parameter associated with the result of a measurement that characterizes the dispersion of the values that could reasonably be attributed to the measurand ${ }^{18}$.

All the uncertainty sources and their influence on the measurand were identified, analyzed and later quantified (volume, repeatability, mass, calibration/linearity, purity). With these data, the combined standard uncertainty was determined and finally the expanded uncertainty was obtained by applying a coverage factor of 2 .

According to the above, uncertainty values for the developed method vary from 0.1 to $1 \mu \mathrm{gL}^{-1}$ for arsenic species concentrations between 1 and $25 \mu \mathrm{gL}^{-1}$.

\section{$\underline{\text { Urine samples analysis }}$}

Urine samples were obtained from occupationally unexposed laboratory staff. Individuals selected for sampling has no history of seafood ingestion or other supplementary source of arsenic. Samples were analyzed for baseline levels arsenic species and the behavior of the method when is applied to real urine samples. The results are consistent with those published by other authors for this type of sample ${ }^{19,20,21}$. The principal characteristics are the almost complete absence of As V and that DMA is the predominant arsenic species present in urine.

The analysis of urine samples using the mobile phase containing 10 $\mathrm{mM} \mathrm{HPO}_{4}^{-2}, \mathrm{H}_{2} \mathrm{PO}_{4}^{-1}$ showed shifts in retention time for the arsenic species compared with the aqueous standards. These changes had little effect on the resolution between adjacent peaks and may be due to the insufficient buffering strength of the mobile phase.

The chromatogram of a sample is shown in Figure 8 and some results in Table 8 . The sample was only diluted 5 times and filtered before being injected into the column.

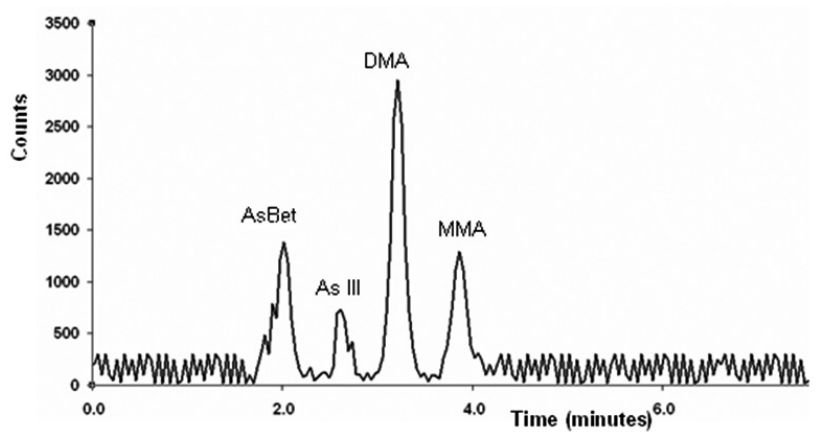

Fig. 8. Human urine sample Chromatogram

Table 8. Arsenic species in urine samples

\begin{tabular}{|c|c|c|c|c|c|}
\hline & $\begin{array}{l}\text { Arsenobetaine } \\
\left(\mu \mathbf{g L}^{-1}\right) \pm \mathbf{U}\end{array}$ & $\begin{array}{c}\text { As III } \\
\left(\mu \mathrm{gL}^{-1}\right) \pm \mathbf{U}\end{array}$ & $\begin{array}{c}\text { As V } \\
\left(\mu \mathrm{gL}^{-1}\right) \pm \mathbf{U}\end{array}$ & $\begin{array}{c}\text { MMA } \\
\left(\mu \mathrm{gL}^{-1}\right) \\
\pm \mathrm{U}\end{array}$ & $\begin{array}{c}\text { DMA } \\
\left(\mu \mathrm{gL}^{-1}\right) \\
\pm \mathbf{U}\end{array}$ \\
\hline M-1 & $1.62 \pm 0.11$ & $1.13 \pm 0.08$ & n.d. & $1.93 \pm 0.28$ & $3.34 \pm 0.40$ \\
\hline M-2 & $1.87 \pm 0.13$ & $1.05 \pm 0.07$ & n.d. & $3.11 \pm 0.19$ & $3.54 \pm 0.18$ \\
\hline M-3 & $3.73 \pm 0.19$ & $1.11 \pm 0.07$ & $4.19 \pm 0.21$ & $3.87 \pm 0.19$ & $4.96 \pm 0.25$ \\
\hline M-4 & $1.11 \pm 0.08$ & $1.76 \pm 0.12$ & n.d. & $1.55 \pm 0.08$ & $2.54 \pm 0.13$ \\
\hline
\end{tabular}

n.d. $=$ not detected

\section{CONCLUSIONS}

A simple, rapid and reliable method for the separation and quantification of several species of arsenic in human urine samples with minimal sample preparation was developed. This method does not require digestion and is not prone to losses and contamination. The time required for sample processing and isocratic chromatographic analysis is about 15 minutes. Good quantification limits were achieved under the analytical conditions developed. The main reasons for the low detection limit of this method are the good resolution of peak separation and the greater sensitivity of the detector. Uncertainty $(<10 \%)$, precision $(<3 \%)$ and accuracy $(>90 \%)$ are good enough for the purposes that this methodology was developed. Experimentally, it was demonstrated that the interference from $\mathrm{NaCl}$ is insignificant $(<0.1 \mathrm{ng}$ for $100 \mu \mathrm{L}$ injection) for urine samples. This methodology can be used to safely evaluate the real levels of arsenic toxicity in the exposed population. Filtration of the urine samples is the only sample preparation required and up to four samples per hour can be analyzed. The methodology can be applied in the population occupationally and environmentally exposed to arsenic and is a contribution to public health in a part of the world where natural arsenic levels are above average.

\section{REFERENCES}

1. Report "Chile, país atractivo para las inversiones mineras", Comisión Chilena del Cobre, Dirección de estudios y políticas públicas. 2013.

2. P. Richter, R. Seguel, I. Ahumada, R. Verdugo, J. Narváez, Y. Shibatac. Chil. Chem. Soc., 49, N 4 (2004): 333-339.

3. Abstracts of scientific papers: Internacional Seminar "El Arsénico en la segunda región, impacto en salud y medioambiente". Faculty of Medicine, University of Antofagasta, Antofagasta, Chile, 2005.

4. F. Coz, Barbara Frazen Reports. Cancer cluster in Chile linked to arsenic contamination. World Report. Vol 379. 2012.

5. C. Ferreccio, "Investigación de los efectos del arsénico en la salud de la II Región: Resultados y Conclusiones", Seminario Internacional."El Arsénico en la II Región”. Faculty of Medicine, University of Antofagasta, Antofagasta, Chile, 2005.

6. F. Queirolo, S. Stegen, J. Mondaca, R. Cortés, R. Rojas, C. Contreras, L. Muñoz, M. J. Schwuger and P. Ostapczuk. The Science of the Total Enviromental, 255, (2000) 85-95.

7. E. Sanz, R. Muñoz-Olivas and C. Cámara, Journal of Chromatography A, 1097, (2005) 1-8.

8. F. Queirolo, S. Stegen, M. Schwuger, P. Ostapczuk, Research on Anthropogenic and Natural Contamination in Northern Chile. International Cooperation. Scientific Series of The International Büro FZ-Jüelich, Vol. 44. 2000.

9. P. Thomas, K. Sniatecki, Fresenius J Anal Chem 351, (1995) 410-414.

10. C. Demesmay, M. Olle, M. Porthault, Fresenius J Anal Chem 348, (1994) 2015-210.

11. Shum SKC, Neddersen R, Houk RS, Analyst 117, (1992) 577-582.

12. Allain P, Jaunault L, Mauras Y, Mermet JM, Delaporte T, Anal Chem 63, (1991) 1497-1498

13. Lange's Handbook of Chemistry (18 $8^{\text {th }}$ Edition) McGraw-Hill. 2005.

14. B. S. Chana, N. J. Smith. Analytica Chimica Acta, 197, (1987) 177-186.

15. T. Sakai, S. Wilbur, W. Bellevue, A routine analysis of toxic arsenic species in urine using HPLC with ICP-MS. Application Note Agilent, 2006.

16. The Fitness for Purpose of Analytical Methods. A Laboratory Guide to Method Validation and Related Topics. EURACHEM. 1998

17. International Vocabulary of Metrology. Basic and General Concepts and Associated Terms (VIM). 3 ${ }^{\text {rd }}$ Edition. BIPM. 2012.

18. Evaluation of Measurement data. Guide to the Expression of Uncertainty in Measurement. First Edition. BIPM. 2008.

19. R. Xie, W. Johnson, S. Spayd, G. Hall, B. Buckley. Analytica Chimica Acta, 578 (2006) 186-194.

20. R. Raml, A. Rumpler, W. Goessler, M. Vahter, L. Li, T. Ochi, K. Francesconi, Toxicology And Applied Pharmacology 222 (2007) 374-380.

21. P. Heitland, H. Koster, Int. J. Hyg. Environ. Health 212 (2009) 432-438.

\section{ACKNOWLEDGMENT}

This study was supported financially by the International Atomic Energy Agency (Project $\mathrm{N}^{\circ} \mathrm{CHI}-7012$ ), which are gratefully acknowledged. 